\title{
Case Report on Clinical Vignette
}

Katherine N Vu DO', Thanh D Hoang DO'*, Alfred F Shwayhat DO', Niels H Olson² and Kane T Walsh²

${ }^{1}$ Department of Endocrinology, Naval Medical Center, San Diego, CA, USA

${ }^{2}$ Department of Pathology, Naval Medical Center, San Diego, CA, USA

Keywords: Adrenal ganglioneuroma; Clinical vignette; Multinodular goiter

\section{Introduction}

Incidental findings of adrenal masses are increasingly found with the use of thoracic and abdominal imaging studies. It is standard practice to determine if these masses are hormonally active or nonfunctional, malignant or benign. Surgical resection is usually recommended for masses larger than $6 \mathrm{~cm}$ in diameter for definitive diagnosis or for functional masses [1]. We report a case of adrenal ganglioneuroma that was incidentally found during a surveillance imaging study.

\section{Case Presentation}

A 79 year old female presented to the endocrine clinic for evaluation of an adrenal incidentaloma that was found during a surveillance imaging study for a known stable aortic aneurysm. Review of systems was positive for intentional weight loss of $30 \mathrm{lbs}$ in the past year; otherwise patient was asymptomatic. She reported no history of headaches, palpitations, flushing, abdominal pain, change in bowel habit or fluctuation of blood pressure. Medical history was notable for non-toxic multinodular goiter, acoustic neuroma, and stable fusiform type B aortic dissection. Vital signs on presentation: blood pressure $145 / 77 \mathrm{~mm} \mathrm{Hg}$, heart rate 81 beats per minute, weight $162 \mathrm{lbs}$. On physical examination, neck was supple, no goiter, buffalo hump or supraclavicular fat pad. Abdomen was benign; no palpable mass or abdominal purple striae. Laboratory studies: plasma aldosterone 3.7 (ref 0.0-30 ng/d), plasma renin 1.23 (1.31-3.95 ng/mL/hr), DHEA 45 (102-1185 ng/dL), DHEAS $29(0-90 \mathrm{mcg} / \mathrm{dL})$, plasma metanephrines $<10(0-82 \mathrm{pg} / \mathrm{mL})$. A $1 \mathrm{mg}$ dexamethasone suppression test was normal. Computed tomography (CT) scan of the abdomen/pelvis with contrast showed a large $6.0 \times 6.5 \mathrm{~cm}$ right adrenal heterogeneous mass with enhanced attentuation at 45 Hounsfield units (Figure 1). Patient underwent resection of the mass with pathology report revealed evidence of ganglion cells, spindle cells and nerve fibers (Figure 2), consistent with an adrenal ganglioneuroma.

\section{Discussion}

This patient's CT scan revealed a large adrenal heterogeneous mass with a Hounsfield more than 10 units. Biochemial testings

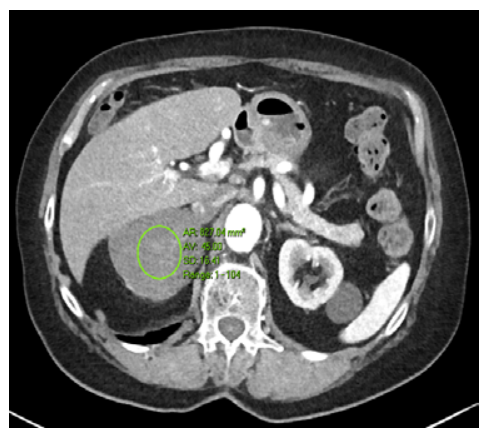

Figure 1: Computed tomography scan of the abdomen/pelvis with contrast showed a large $6.0 \times 6.5 \mathrm{~cm}$ right adrenal heterogeneous mass with enhanced attentuation at 45 Hounsdfield units. showed no evidence of pheochromocytoma, hypercortisolism, or hyperaldosteronism. Given the CT findings above, we were originally concerned for possible adrenal carcinoma although biochemical testings were normal. The patient underwent laparoscopic adrenalectomy successfully and pathology revealed a benign ganglionneuroma as seen in Figure 2.

Adrenal ganglioneuroma (AGN) is a rare, benign, differentiated neurogenic tumor that can mimic other adrenal neoplasms. The tumor has no hormonal hypersecretion. CT scan imaging characteristics of AGNs usually help to distinguish them from other adrenal neoplasms which include: (a) low attenuated ( $<40$ Houndfield units) homogeneous mass in the precontrast phase (b) progressive enhancement on postcontrast phase and delayed images (c) presence of punctuate or discrete calcification in about 50 percent of cases [2-4]. Adrenal adenomas usually have similar morphology to AGN, however they are often smaller in size with characteristic washout of more than $50 \%$ contrast on delayed images; whereas adrenocortical carcinomas are typically large $(>5 \mathrm{~cm})$, heterogenous on precontrast images with inhomogenous contrast enhancement.

In conclusion, it is crucial to distinguish benign AGN from adrenal carcinoma and pheochromocytoma in patients presenting with a large adrenal mass. The final diagnosis is usually made with surgical intervention. Isolated AGNs do not produce catecholamine and they have CT imaging characteristics as described above. The nature of AGNs is usually benign and has good prognosis.

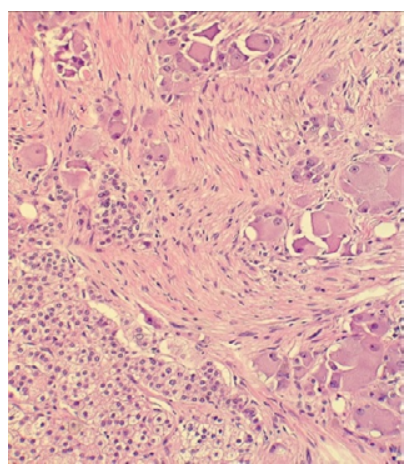

Figure 2: Surgical specimen showed evidence of ganglion cells, spindle cells and nerve fibers, consistent with adrenal ganglioneuroma.

*Corresponding author: Thanh D Hoang, Division of Endocrinology; Nava Medical Center, San Diego 34800 Bob Wilson Drive, Suite 203; San Diego, CA 92134-3203,USA,Tel: 619-532-7375; Fax: 619-532-5472; E-mail: thanh.hoang@med.navy.mil

Received July 11, 2014; Accepted August 08, 2014; Published August 11, 2014

Citation: Katherine N Vu DO, Thanh D Hoang DO, Alfred F Shwayhat DO, Olson $\mathrm{NH}$, Walsh KT (2014) Case Report on Clinical Vignette. J Clin Case Rep 4: 404. doi:10.4172/2165-7920.1000404

Copyright: ( 2014 Katherine N Vu DO, et al. This is an open-access article distributed under the terms of the Creative Commons Attribution License, which permits unrestricted use, distribution, and reproduction in any medium, provided the original author and source are credited. 
Citation: Katherine N Vu DO, Thanh D Hoang DO, Alfred F Shwayhat DO, Olson NH, Walsh KT (2014) Case Report on Clinical Vignette. J Clin Case Rep 4: 404. doi:10.4172/2165-7920.1000404

\section{Disclaimer}

The views expressed in this article are those of the authors and do not necessarily reflect the official policy or position of the Department of the Navy, Department of Defense, or the U.S. Government. We certify that all individuals who qualify as authors have been listed; that each has participated in the conception and design of this work, the analysis of date, the writing of the document, and the approval of the submission of this version; that the document represents valid work; that if we used information derived from another source, we obtained all necessary approvals to use it and made appropriate acknowledgements in the document; and that each takes public responsibility for it.

\section{References}

1. Nieman LK (2010) Approach to the patient with an adrenal incidentaloma. J Clin Endocrinol Metab 95: 4106-4113.

2. Shawa H, Elsayes KM, Javadi S, Morani A, Williams MD, et al. (2014) Adrena ganglioneuroma: features and outcomes of 27 cases at a referral cancer centre. Clin Endocrinol (Oxf) 80: 342-347.

3. Linos D, Tsirlis T, Kapralou A, Kiriakopoulos A, Tsakayannis D, et al. (2011) Adrenal ganglioneuromas: incidentalomas with misleading clinical and imaging features. Surgery 149: 99-105.

4. Maweja S, Materne R, Detrembleur N, de Leval L, Defechereux T, et al. (2007) Adrenal ganglioneuroma. Am J Surg 194: 683-684. 